\title{
An Iceberg No More: Rising Waters of Chronic Vascular Diseases
}

The iceberg once seemed the perfect image to represent the global dilemma of vascular diseases: the apex of heart disease, stroke and chronic kidney disease was visible over the horizon's edge, with the bloated and often under-diagnosed epidemics of hypertension, diabetes mellitus, and common risk factors lurking in the depths below. The iceberg also floated in colder waters, a handy metaphor for the chronic disease pattern that was sweeping across the industrialized north.

But an image more apropos of today's alarming reality may be the swiftly melting iceberg, diluting the rigid lines between one vascular condition and another, until co-morbidity of diseases and their common risk factors present the greatest threat of all.

As with the real-life iceberg meltdown, these unleashed risk factors are raising tides across the globe, spreading the epidemic of chronic diseases to the shores of developing countries. Most chronic disease deaths now occur in low and middle income countries, and it is there that death rates are rising fastest. In fact, by 2005, chronic diseases in general caused over 35 million or $60 \%$ of all deaths worldwide.[1] Except in sub-Saharan Africa, they had overtaken infectious diseases as the main cause of morbidity and mortality - a majority of them conditions that affect the vascular system, with coronary heart disease the world's number one killer.[2,3]

The World Health Organization (WHO) predicts that between 2005 and 2015, 388 million people worldwide will die from chronic diseas$\mathrm{es}$, with diabetes deaths presenting the most alarming increases.

WHO Predictions for Chronic Disease (ChD) Deaths 2005-2015

\begin{tabular}{lcrcc} 
Countries & $\begin{array}{l}\text { ChD Deaths } \\
\text { (millions) }\end{array}$ & $\begin{array}{l}\text { ChD } \\
\text { Deaths }\end{array}$ & $\begin{array}{l}\text { Diabetes } \\
\text { Deaths }\end{array}$ & $\begin{array}{l}\text { Other Causes } \\
\text { of Death }\end{array}$ \\
\hline Low Income & 137 & $+20 \%$ & $+39 \%$ & $+4.0 \%$ \\
$\begin{array}{l}\text { Lower Middle } \\
\text { Income }\end{array}$ & 144 & $+15 \%$ & $+48 \%$ & $+2.0 \%$ \\
$\begin{array}{l}\text { Upper Middle } \\
\text { Income }\end{array}$ & 31 & $+21 \%$ & $+80 \%$ & $-7.0 \%$ \\
High Income & 76 & $+11 \%$ & $+53 \%$ & $+0.1 \%$ \\
Africa & 28 & $+27 \%$ & $+42 \%$ & $+6.0 \%$ \\
Americas & 53 & +17 & $+80 \%$ & $-8.0 \%$
\end{tabular}

Source: World Health Organization. Preventing chronic diseases: A vital investment. Geneva: WHO; 2005.

Furthermore, the organization estimates $80 \%$ of premature heart disease, stroke and type 2 diabetes could be prevented by addressing common risk factors such as diet, physical inactivity and smoking.[1] Yet, coordinated national and international prevention strategies are sorely lacking; chronic disease programs are woefully underfunded; $[1,4]$ and integrated management of shared risk factors remains on the theoretical drawing board.

In 2005, this situation prompted five international organizations dedicated to chronic vascular diseases to meet in Bellagio, Italy, to formulate a comprehensive approach. They created a joint framework, and agreed to develop a five-year plan to accelerate implementation of preventive strategies. They also decided to seek new high-profile advocates to shine the spotlight on these diseases, absent as they were from the Millennium Development Goals. As an important step, Dr Giuseppe Remuzzi, of the International Society of Nephrology, called for the international community to support increased epidemiological research capacities, especially in developing countries, to better understand the behavior of the worldwide epidemic.[3]

\section{...diluting the rigid lines between one vascular condition and another, until co-morbidity of diseases and their common risk factors present the greatest threat of all.}

This is where MEDICC Review's current issue begins, by bringing you substantive examples of Cuban research in the field (Epidemiology of Cardiovascular Diseases in Cuba, 1970 to 2006; Cardiovascular Risk among Older Women in a Havana Health Area; Association between Blood Lipids and Types of Stroke). The article, Prevalence of Obesity and its Association with Chronic Kidney Disease, Hypertension and Diabetes Mellitus. Isle of Youth Study (ISYS), Cuba is based on prize-winning work (Cuba's National Health Science Prizes 2007), whose results undoubtedly will contribute to reforming health sector strategies for chronic vascular diseases and their common risk factors (Chronic Vascular Diseases in Cuba: Strategies for 2015; Cubans' Deadly Diet: A Wakeup Call).

We also publish another side of chronic disease, exploring Cuba's regional partnership for vision restoration (Sight for Sore Eyes); plus an interview with Dr Pedro Valdés of the Cuban Neuroscience Center (Riding the Brainwaves of Cuban Science).

Finally, returning to that iceberg: for this April's World Health Day, devoted to protecting health from climate change, we reproduce (online only) an article by Dr Paulo Ortiz Bultó - Assessment of Human Health Vulnerability to Climate Variability and Change in Cuba - a taste of an upcoming issue on health, environment, and climate change. - 1 -

\section{The Editors}

1. World Health Organization. Preventing chronic diseases: A vital investment. Geneva: WHO; 2005.

2. Smith $\mathrm{S}$, Jackson $\mathrm{R}$, Pearson $\mathrm{T}$, et al. Principles for national and regional guidelines on cardiovascular disease prevention. Circulation. 2004;109:3112-21.

3. Dirks $\mathrm{JH}$, Robinson SW, Alderman $\mathrm{M}$, et al. Meeting report on the Bellagio Conference 'prevention of vascular diseases in the emerging world: an approach to global health equity'. Kidney Int. 2006;70:1397-402.

4. Yach D, Hawkes C, Gould L, Hofman KJ. The global burden of chronic diseases: overcoming impediments to prevention and control. JAMA. 2004;291:2616-22. 